\title{
Philippe Djian, un artisan du verbe aux marges de la littérature
}

\begin{abstract}
:
This article tries to present a controversial author: Philippe Djian.

Famous but paradoxically unknown, he occupies a special position in contemporary french literature.

Literary institution has long considered his works as popular lietrature. His work is classified by criticism as resolutely modern. Relying on American inspiration, it reveals a demanding way of writing, an original universe that suits his time. Djian's works deserve to raise debate and ask interesting questions: where are the frontiers between literature and popular literature situated? Does literary inspiration have limits? When a writer becomes an author? Key-words : Literature, writing, popular literature, America, influence.
\end{abstract}

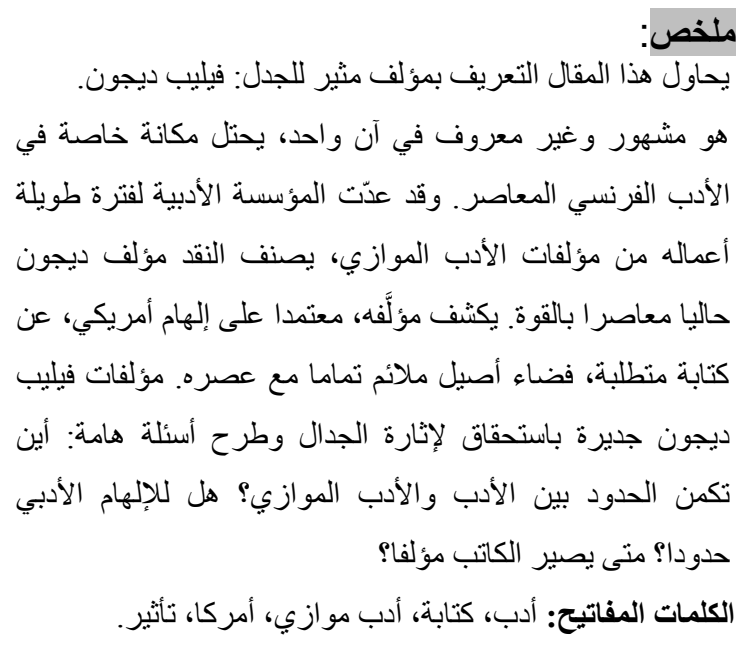

\section{Introduction :}

1981-2014. Cela fait plus de trente ans maintenant que Philippe Djian occupe une place à part dans le paysage littéraire français. Trente ans que l'auteur et l'œuvre passionnent, énervent ou révulsent. Trente ans qu'ils sont incontournables pour certains, insupportables pour d'autres. Trente ans que Djian est un auteur « hors norme », au sens littéral du terme, en dehors de la normalité littéraire, à jamais marginal. 
Même s'il a reçu le Prix Interallié pour son roman "Oh... " en 2012, Djian reste trop souvent mal aimé et mal jugé par l'institution littéraire, victime inlassable du double succès populaire rencontré dans les années quatrevingt lors de l'adaptation cinématographique de son roman $37^{\circ} 2$ le matin et dans les années quatre-vingt -dix lors de sa collaboration avec le chanteur suisse Stephan Eicher dont il signe les textes.

Djian se joue des critiques et de son image. Une véritable mystique entoure son œuvre et son personnage, parce qu'ils sont mal connus, entachés par trois décennies d'idées reçus et de diabolisation. Il n'est donc pas inutile de (re)découvrir un auteur à l'écriture exigeante tenu aux marges de la critique littéraire universitaire.

\section{Pour une littérature rock}

1986. Le grand public français se passionne pour le dernier film de Jean-Jacques Beinex, $37^{\circ} 2$ le matin, adapté du troisième roman d'un jeune auteur : Philippe Djian. Le succès populaire est énorme et le monde des lettres découvre incrédule cet auteur qui s'affiche en blouson en cuir et lunettes noires et préfère sans complexe les plateaux des Enfants $d u$ rock $^{(1)}$, d'Antoine de Caunes à ceux d'Apostrophes, l'émission littéraire de Bernard Pivot ${ }^{(2)}$.

Djian ne méprise pas le milieu littéraire mais il lui est totalement étranger : Ancien gardien d'autoroute, baroudeur sur les sentiers colombiens ou dans les grands espaces états-uniens, son entrée en littérature tient de la méprise : Djian rêve d'être journaliste ou musicien et écrit tantôt par ennui, tantôt aussi parce que l'acte d'écrire lui fait du bien. Ses premières nouvelles sont cependant retenues par les éditions Bernard Barrault, séduites par un style résolument moderne. Et pour cause : Le regard de l'auteur sur le monde, tantôt cynique, tantôt tendre, se révèle par une écriture où l'humour, l'ironie et une indéniable poésie se mêlent à une pratique subversive de la langue: Djian cultive volontairement l'oralité, les fautes de syntaxes...et les anglicismes. Et ce n'est pas tout: ses personnages sont des marginaux, baptisés de prénoms anglo-saxons. Ils ingurgitent de la nourriture fast-food, des litres de bière et ont une forte addiction au sexe et à la musique. L'univers romanesque de Djian est étranger à ce que la littérature française a toujours produit. L'auteur innove et donne naissance à ce que l'on appelle désormais : La littérature rock.

Patrice Bollon tente de théoriser ce mouvement et reconnait dans les premiers écrits de Djian - de 1981 à 1986 surtout- " un spectacle de l'excès, de la frustration, une mise en scène de fantasme, [faisant] du rock un art de l'instant, un art nihiliste qui ne vit que dans l'irrésolution, indissolublement lié à la perte et à la mort. [...] [Un art qui] plong[e] dans cette part maudite de nos sentiments et leur donne une expression» [1] Pour Philippe Lacoche, l'écriture de Djian peut être qualifiée de rock dans la mesure où elle accorde la part belle au rythme et met en texte univers ou le léger se fait tragique et où l'innocence reste joyeuse au sein de la catastrophe. 
$\mathrm{Si}$ aujourd'hui le roman rock est très répandu dans la littérature française ${ }^{(3)}$, ce style et cette vision du monde particuliers étaient inédits dans les années quatre-vingt et Djian a appris à ces dépends qu'en France "le statut d'écrivain exclut d'office toute marginalité culturelle ou sociale. »[2]

Pourtant cette étrangeté plait au public. Djian écrit en effet la langue orale et populaire - non pas en terme de classe sociale mais en tant que partagée par le plus grand nombre- de ses lecteurs. Il possède la même passion qu'eux pour la musique rock, habille ses personnages de jeans et de tee-shirts, fait des fautes de syntaxe, relaie les rêves américains diffusés sur le petit écran. En somme, il offre à cette génération de trentenaires avec laquelle il a grandi et a eu en partage les utopies de Mai 68, du mouvement hippie, du rock, de la libération sexuelle, les livres qu'elle veut lire. Djian devient donc, pour la critique journalistique, l'écrivain de toute une génération.

Mais le soutien populaire ne légitime pas aux yeux de l'institution littéraire l'auteur et l'œuvre. Au contraire, le succès commercial de ses premiers romans a tôt fait de discréditer la valeur esthétique ou littéraire de son œuvre que la critique classe avec empressement dans les limbes de la paralittérature et de la culture de masse. Véronique Campa explique qu'en effet toute œuvre qui «marche » d'un point de vue commercial est "associée de fait à un aspect mécréant » qui disqualifie l'œuvre et sous-entend qu'elle est «bas de gamme. »[3] Il y a immanquablement dans les qualifications de paralittérature et de culture de masse un jugement méprisant visant tant le côté de la production que celui de la réception : L'auteur n'a en effet pas de talent, n'a pour ambition que de distraire et d'être gracieusement rétribué. Le roman n'est pas une œuvre mais un produit. Le lecteur est assimilé à un consommateur sans culture ni esprit critique, incapable d'apprécier la vraie littérature. Cette équation sous-tend en filigrane, comme le rappelle Marc Angenot, que "la production ainsi mise au ban est "entièrement occultée au regard scientifique et ne semble pouvoir faire l'objet que d'un discours dégradé, plaisant, anecdotique »[4]. Ceci est on ne peut plus vrai pour Philippe Djian. Après trente ans de carrière et une trentaine d'œuvres publiées, rares sont encore les universitaires ayant analysé son œuvre.

Djian n'est pas homme à mendier l'assentiment des gens de lettres. Au contraire, il n'a de cesse d'ironiser sur ce thème. En 1996 dans Entre nous soit dit, conversations avec Jean-Louis Ezine, il déclare: "Pendant que Gracq, Le Clézio ou Nathalie Sarraute s'arrachent la fine fleur du lectorat français, je me goberge dans la fange majoritaire tout seul comme un chanoine. "[5] Il pousse encore davantage la provocation en disant préférer le succès commercial immédiat à la reconnaissance posthume et commet l'ultime sacrilège de militer pour une littérature divertissante qui délaisse la tradition française et se met à rêver d'Amérique. 


\section{Rêve américain}

L'intelligentsia française l'a établi et érigé en Loi : l'Amérique et la Culture sont deux univers antithétiques, deux droites parallèles qui doivent se résoudre à ne jamais se rencontrer. Richard Kuisel résume la position française, de façon certes un peu simpliste, en ces termes :

Les Français [...] se sentent culturellement supérieurs et appelés à répandre la lumière sur le monde.[...] La base de l'antiaméricanisme est culturelle et s'appuie sur le désir de protéger et disséminer la civilisation [qui] implique une éducation humaniste et classique, un style de vie qui, va avec le bon goût, la flânerie, le vin, la grande cuisine, une philosophie sceptique, tragique, réaliste et une langue d'une grande qualité. [6]

A l'heure où les Etats-Unis sont toujours sous le poids des cabales contre leur culture, réduite à Mac Donalds et Coca-Cola, Djian, trouble-fête, s'élève et rappelle le génie littéraire des prix Nobel Hemingway et Faulkner mais également des méconnus Brautigan ou Carver. Là où Jean-Paul Sartre dénonçait « une violation intellectuelle »[7], Djian, comme Dubois ou Daeninckx, trouve un terrain d'inspiration à la mesure des grands espaces américains. Il nous suggère que l'inspiration peut venir de partout et que la littérature française ne doit pas se complaire, pauvre narcisse, dans une autosatisfaction nombriliste.

Djian devient une cible des anti-américanistes qui, à l'instar de Jack Lang, dénoncent «l'impérialisme culturel [américain] qui s'approprie les consciences, les façons de penser et les façons de vivre »[8] ou encore déplorent, comme Jean-Pierre Chevènement que «L'Amérique [soit] devenue le dernier horizon de la jeunesse. »[9]

Aussi, la critique s'interroge : L'Amérique, déjà présente sur le petit comme sur le grand écran, sur les ondes radiophoniques, doit-elle également se retrouver impunément en librairie, sous la plume d'un auteur natif de la patrie des Droits de l'Homme, prêt à échanger Marianne contre l'Oncle Sam (4) $^{(4)}$

C'est pourquoi Djian semble faire volontairement partie de ceux qui « tirent la culture vers la bas », qui vendent la France à l'ennemi américain en poussant ces lecteurs à cesser de « pens[er] selon Montaigne ou Diderot. »[10] Mais là où certains interprètent le Babel culturel comme une malédiction, d'autres, à l'instar de Djian, y trouvent une incommensurable bénédiction : celle de la richesse du brassage et du métissage. De l'ouverture sur le monde. C'est en ce sens que Catherine Moreau analyse dans Plans Rapprochés, l'indéniable nouveauté apportée par Djian à la littérature française :

L'écriture de Djian, quand elle est apparue dans les années 1980 a certainement contribué à changer les mentalités, dans la mesure où 
elle se posait en rupture par rapport à un certain horizon d'attentes [...] car, lorsque les premiers romans de Djian paraissent en France ils connotent d'emblée un américanisme qui est à la fois une influence et une modernité. [...] Les livres de Djian connotent "étranger " et, étendant à la littérature un phénomène populaire oral en train de se propager, ${ }^{(5)}$ ils "sonnent» résolument "moderne. "[...] En " changeant » sa propre langue, [l'auteur] change aussi une vision du monde, et à fortiori de la littérature. Il y a là indéniablement une esthétique nouvelle (toujours dans le contexte culturel que constituent les années 1980) qui bouleverse les normes en place.[11]

C'est pourquoi Djian assume les étiquettes que la critique journalistique lui colle depuis trente ans: héritier de la Beat Generation, écrivain américain. A la lecture de ses romans, ces étiquettes se justifient d'ailleurs : Bleu comme l'Enfer reprend le schéma des road-movies américains et les personnages, enivrés d'alcool, de musique et de femmes, ne sont pas sans rappeler la bande d'hédonistes conduite d'est en ouest sur les routes d'Amérique par Dean Moriaty dans le chef-d'œuvre de Kerouac, Sur la Route. $37^{\circ} 2$ le matin dans lequel une serveuse à demi folle s'éprend d'un écrivain raté, reprend les grandes lignes de Demande à la Poussière de John Fante. Sotos, explore le monde de la corrida en hommage à la passion d'Ernest Hemingway. Qui sera par ailleurs évoqué comme un personnage dans Impardonnables en 2009. En 2003, Frictions offre quatre nouvelles comme autant d'instantanés de vie quotidienne, à la manière de Raymond Carver. En 2002, dans ça c'est un baiser, Djian procède à l'alternance des narrateurs à la manière de William Faulkner dans Tandis que j'agonise. En 2010, dans Incidences, il met en texte un serial-killer qui rappelle en tout point Patrick Bateman, le monstrueux personnage d'American Psycho de Brett Easton Ellis. Djian assume explicitement sa position :

Ecoutez-les, ils sont tous en train de relire Flaubert, Stendhal ou Dostoïevski et n'ont de livres de chevet que Chateaubriand, Homère ou Saint-Simon. Plus ils sont bêtes et stupides, plus ils ont de bonnes lectures [...] [moi] je pourrais donner mille fois Maupassant en échange de contemporain dont le nom ne figure même pas au Dictionnaire des Auteurs. [12]

La mythologie littéraire de l'écrivain est composée d'auteurs pour la plupart d'auteurs marginaux américains. Djian les a découverts entre sa vingtième et sa trentième année. Il assimile cette décennie à une "sorte d'ivresse permanente » [passées] sous une pluie de météorites ». Depuis, il n'a jamais manqué de souligner l'admiration qu'il voue aux auteurs qui lui ont transmis l'amour de la littérature: citation leurs appartenant données en 
exergue de ses romans, mise en abyme de la lecture de leurs romans dans ses propres romans. En 2002, Philippe Djian règle définitivement sa dette à ses inspirateurs avec Ardoises, livre sans nulle précision générique mais dont la tonalité est très proche de l'essai. Il y disserte de ses amours littéraires et encense comme il pense devoir le faire ses maîtres: Salinger, Kerouac, Melville, Miller, Faulkner, Hemingway, Brautigan, Carver... et deux français à la plume résolument moderne Céline et Cendrars.

Ardoise n'est pas un essai: Djian trouve une nouvelle manière de parler de la littérature : à la précision scientifique et à l'exposé théorique qui dissèque l'écriture ou l'œuvre de tel ou tel auteur, Djian place l'intérêt pour le livre sur le terrain du coup de foudre et de l'indicible.

Pour une démocratisation de la littérature

Pour Djian la beauté d'une œuvre ne se mesure pas à l'impeccable maîtrise de la langue où à la noblesse du thème traité mais bien à l'émotion transmise au lecteur. Il déclare : "Mon approche de la littérature n'a pas été intellectuelle mais viscérale.[13] Cette position sous-tend une redéfinition du génie littéraire et met à jour une conception qui balaie les critiques que Djian a lui-même pu recevoir et qui brouille un peu plus les frontières entre littérature et paralittérature. Il revient au lecteur de définir ce qui pour lui est beau et digne d'être nommé «grand livre » sans se soucier des lobbies de la culture bien -pensante. A ce sujet, l'auteur déclare :

Un auteur n'a d'intérêt que dans la mesure où il révèle ce qu'il ya de et de plus subtil en nous. Si c'est Flaubert, allons-y pour Flaubert. Mais si c'est Brautigan [...] ne vous laissez pas submerger par cet écourante sentiment d'infériorité que rien ne justifie, si ce n'est le poids d'une culture si convenue et si largement partagée qu'elle en devient obscène. [14]

Djian milite donc pour une démocratisation de l'institution littéraire : aux pressions faites par l'intelligentsia française, omnipotente tant sur le domaine du savoir que sur celui du bon goût, la masse des lecteurs, souvent méprisée parce que considérée comme « inculte » voire profane, doit être fière de ses amours livresques et les défendre corps et âme.

Djian s'approprie là encore une idée largement diffusée par des auteurs américains comme Charles Bukowski selon laquelle la littérature ne doit pas être réservée à une fange cultivée de la population. Mais il va encore plus loin et il milite pour une littérature de divertissement, au sens américain d'entertainment, y voyant une source possible de renouvellement de la littérature, associant culture, plaisir esthétique et détente. C'est cette idée qui a motivé la création du roman-télé Doggy bag, vaste ensemble de six romans conçus à la manière des séries américaines. Djian explique : "J'ai essayé de créer en littérature ce dont les gens raffolent actuellement: une série. Je n'avais aucune idée de ce que j'allais faire mais je me suis dit : si les gens aiment ça, il faut leur donner ça. »[15] 
Les propos et le projet de Djian confirment le constat déplorable établi par Hannah Arendt dans La crise de la culture, selon lequel les objets culturels sont inexorablement entraînés sur la pente du divertissement. Pourtant, Djian prend le contrepied de cette position et soutient que le divertissement est une façon d'élargir le public traditionnel, d'amener à la littérature des personnes qui n'en ont ni la pratique, ni la culture :

J'écris des livres populaires qui peuvent sembler même à certains très vulgaires. Mais je suis convaincu qu'il faut le faire pour aller audevant des lecteurs.[...] Si j'étais Maria Callas, j'aurais autant de plaisir à chanter des airs populaires que du Verdi, j'y mettrai autant de talent, de joie, de plaisir Et si les airs napolitains avaient plus de chance de rentrer dans des maisons où la musique ne pénètre jamais, eh bien je renoncerai à Verdi et je choisirai les chants napolitains.[16]

Ce souci incessant du public témoigne d'une littérature généreuse qui place à égalité l'auteur et le lecteur, le bonheur d'écrire et le plaisir de lire.

Le plaisir de lire Djian réside sans doute dans la découverte d'un style assez singulier qui reste contre toute attente, d'inspiration française: le critique Jean-Paul Richard y décèle une petite musique digne de celle de Louis Ferdinand Céline.

Pourtant, le style djianien n'a cessé d'évoluer.

Richard qualifiait l'écriture djanienne des premiers romans de « séduisante (...) parce que vitale, élastique, faite de fièvre et de rebond. »[17] Il note parmi ses caractéristiques un verbe marqué par «la discontinuité, le heurt» "une parole, orale familière, chargée d'affectivité », "un humour excessif. ॥

Il est vrai que l'on y trouve une façon particulière de cultiver les comparaisons improbables, à la limite du surréalisme, qui surprennent le lecteur et confèrent à l'écriture djanienne une indéniable poésie. Nous ne sommes pas loin des étincelles poétiques qu'André Breton admirait tant chez Lautréamont. La musique djanienne des premières œuvres peut naître de «la rencontre fortuite sur une table de dissection d'une machine à coudre et d'un parapluie »[18] ou encore de synesthésies dignes de Baudelaire.

Pourtant, en 1991, le roman Lent dehors marque un tournant stylistique. L'auteur s'assujettit aux conventions linguistiques et aux normes romanesques. Les intrigues deviennent minimalistes et l'auteur concentre ses efforts sur la phrase, véritable matrice de l'émotion, persuadé, que le monde entier peut tenir en elle. Depuis, l'obsession de la phrase est devenu, roman après roman, quête d'une certaine perfection. Djian pense que c'est par elle que la littérature remplit sa fonction ordonnatrice et parvient à remettre «un peu d'harmonie dans le chaos du monde. [19] 
Cette harmonie provient, chez Djian comme chez Céline, d'une musique interne au texte, le rythme étant la préoccupation obsessionnelle de l'auteur. Il explique dans Ardoise que depuis Kerouac, qui avait une passion sans pareil pour le jazz, "une grande partie de la culture est transmise par les musiciens et les chanteurs, aussi bien la poésie que les messages poétiques. L'oreille est habituée à recevoir la bonne parole sous une forme particulière : l'élocution rythmée. "[20] Djian considère donc l'écriture comme "une petite musique qu'il essaie de recomposer. »[21] Une musique qui doit moins à la beauté ou à la rareté des mots choisis qu'à «l'harmonie qui s'opère entre les uns et les autres. » [22]

Cette passion pour les mots et le rythme a conduit Djian à écrire les paroles des chansons de son ami Stephan Eicher depuis 1989. Cet exercice particulier permet à l'auteur de toucher à la grâce en voyant "le cadavre [de ses] textes [...] parcourus d'éclair.»[23] Quête du rythme et des sonorités, l'écriture de chanson

Certes les détracteurs de Philippe Djian seront encore difficiles à convaincre. Ils argumenteront que les intrigues sont simplistes: histoire d'amour banale qui accorde la part belle aux relations sexuelles, description inlassable de rapports amoureux, amicaux, filiaux... cependant l'exploration d'infimes plaisirs quotidiens, l'attention sensible à la beauté de l'instant décrit fait tendre le texte djanien, à sa décharge vers une poésie hédoniste et offre au lecteur un véritable plaisir esthétique. L'écriture de Philippe Djian relève d'une exigence : démocratiser la beauté du texte, la rendre accessible à tous car digne de tous, la sortir du narcissique hermétisme pour l'offrir en partage au plus grand nombre.

Alors? Paralittérature ? Culture de masse? Non, sans doute mais une écriture résolument moderne, qui quête ses valeurs esthétiques dans le quotidien de ce qui l'entoure. Une écriture en phase avec le vécu d'une époque mondialiste où les nouvelles technologies enfantent de nouveaux rapports sociaux... Une écriture exigeante donc, qui pourrait bien, dans quelques années et à la surprise générale faire de Philippe Djian un incontournable classique.

\section{Notes :}

1- Emission télévisée diffusée en France de 1982 à 1988, Les enfants du rock était un magazine de pop-culture qui évoquait l'art moderne, le cinéma, la bande-dessinée, la musique.)

2- Diffusée de 1975 à 1990.

3-Citons pour exemple des auteurs comme Virgine Despentes, Nicolas Rey, Frédéric Beigbeder, Vincent Ravalec qui font partie de cette mouvance. 
4- En 2010, Philippe Djian trouve toujours utile de répondre indirectement à ces accusations d'américanisme par le biais du héros narrateur de son roman Incidences. Le personnage, professeur de littérature fait découvrir à ces étudiants John Gardner " fut-il accusé de traître à la littérature française et d'ultra-américaniste forcené. » DJIAN, P., Incidences, Paris, Gallimard, 2010, p. 15 .

5- Le phénomène oral et populaire sous-entendu par Catherine Moreau est l'anglicisme.

\section{Références bibliographiques :}

[1] BOLLON, P., « un théâtre de la cruauté », Dossier « les écrivains rock », in Le magazine littéraire, $\mathrm{n}^{\circ} 404$, novembre 2001. p..25

[2]DJIAN, P., Entre nous soit dit, conversations avec Jean-Louis Ezine, Paris, Plon,1995, Pocket,1997, p.10.

[3]CAMPA, V., « la culture de masse », article en ligne :

[www.semionet.com.],p.4

[4] Ibid., p.11.

[5] DJIAN, P., Entre nous soit dit, (entretiens avec Jean-Louis EZINE), Paris, Plon,1995, Pocket,1997, p.25.

[6] Ibid., p.29.

[7] KUISEL, R., le miroir américain, cinquante ans de regards français sur l'Amérique, traduit de l'américain par Elie Rob-Nicoud, Paris, édition Lattès, 1996. p. 380-381

[8]Voir à ce sujet: ROGER, P., L'Ennemi Américain, Généalogie de l'antiaméricanisme français, Paris, éd.du Seuil, collection «la couleur des idées $\gg, 2002$.

[9] KUISEL, R.,op.cit., p. 354.

[10] Ibid., p.354-355.

[11] MOREAU C., Plans rapprochés, Charenton, Les singuliers littérature, Flohic, 2000, p.243.

[12] DJIAN, P., Ardoise, Paris, Juliard, 2002,( pocket), p. 17.

[13] DJIAN, P., Entre nous soit dit, op.cit., p.22.

[14] DJIAN, P, Ardoise, op.cit, p.17.

[15] DJIAN, P., in CHATEL, V., « écrire la vibration du monde : entretien avec Philippe Djian », Le Nouvelliste, 15 juillet 2008.

[16] DJIAN, Philippe in CROM, Nathalie, op.cit .

[17]RICHARD, J-P, L'Etat des choses, Paris, Gallimard, 1990, p.148.

[18] LAUTREAMONT, Les Chants de Maldoror, in Euvres complètes, éd.

Guy Levis Manos, 1938, p.256.

[19] DJIAN, P., Ardoise, op.cit., p.60

[20] Ibid., p.60.

[21] DJIAN, P., Entre nous soit dit, op.cit., p.80

[22] DJIAN, P., Ardoise, op.cit. p.61. 
[23] DJIAN, P., Entre nous soit dit, op.cit., p.159.

Bibliographie :

Euvres littéraires de l'auteur :

DJIAN P.,

Bleu comme l'enfer, Paris, roman Bernard Barrault, ,1983 (J'ai lu)

372 le matin, Paris, Bernard Barrault, 1985. (J'ai lu)

Lent dehors, roman, Paris, Bernard Barrault, 1991.(Folio.)

Assassins, roman, Paris, Gallimard, 1993 (Folio)

Entre nous soit dit (Entretiens avec Jean-Louis Ezine), Paris, Plon, 1995,

(Pocket).

Ardoise, Paris, Julliard, 2002 (Pocket)

Ca, c'est un baiser, Paris, Gallimard, 2002.

Frictions, nouvelle, Paris, Gallimard, 2003 (Folio)

Impardonnables, Paris, Gallimard, 2009.(Folio)

Incidences, Paris, Gallimard, 2010.

Vengeances, Paris, Gallimard, 2011.

ouvrages et articles critiques :

ANGENOT M., «Qu'est-ce que la paralittérature ? », in études littéraires, volume 7, numéro, avril 1979, p : 9-22.

CAMPA V., « la culture de masse »,article en ligne : [www.semionet.com.]

KUISEL, R. Le miroir américain, Cinquante ans de regard français sur

l'Amérique, Paris, Lattès, 1996.

RICHARD J-P., L'Etat des choses, Paris, Gallimard, 1990.

ROGER P., L'Ennemi Américain, Généalogie de l'antiaméricanisme français,

Paris, éd.du Seuil, collection « la couleur des idées »,2002.

Ouvrages complémentaires:

BOUDJEDRA M., Djian, Essai, Paris, Éd. du Rocher, Coll. Domaine français, 1992

FLOHIC C., Philippe Djian revisité, Entretiens, Paris, Flohic, Coll. Les singuliers Littérature, 2000.

MOREAU C.,- Plans Rapprochés, Essais, Paris, Flohic, collections les singuliers littérature, 2000.

-Au plus près, Paris, La passe du vent, 1999. 